\title{
Aircraft noise: Accounting for changes in air traffic with time of $\operatorname{day}^{\text {a) }}$
}

\author{
Beat Schäffer, ${ }^{\text {b) }}$ Rudolf Bütikofer, Stefan Plüss, and Georg Thomann ${ }^{\text {c) }}$ \\ Empa, Swiss Federal Laboratories for Materials Science and Technology, Laboratory of Acoustics/Noise \\ Control, Überlandstrasse 129, 8600 Dübendorf, Switzerland
}

(Received 19 April 2010; revised 29 September 2010; accepted 23 October 2010)

\begin{abstract}
Aircraft noise contours are estimated using model calculations and, due to their impact on land use planning, they need to be highly accurate. During night time, not only the number and dominant types of aircraft may differ from daytime but also the flight paths flown may differ. To determine to which detail these variations in flight paths need to be considered, calculations were performed exemplarily for two airports using all available radar data over 1 year, taking into account their changes over the day. The results of this approach were compared with results of a simpler approach which does not consider such changes. While both calculations yielded similar results for the day and close to the airport, differences increased with distance as well as with the period of day (day $<$ first hour of the night $<$ second hour of the night, respectively, day $<$ evening $<$ night). Only the detailed calculation always accounted for the flight path changes in full detail. Possible legal consequences of such different modeling approaches are estimated, and the model results are compared to monitoring measurements. Finally, the situations for which the simpler approach is sufficiently accurate are ascertained. (C) 2011 Acoustical Society of America.
\end{abstract}

[DOI: $10.1121 / 1.3518729]$

PACS number(s): 43.50.Lj, 43.50.Rq, 43.50.Qp [KVH]

Pages: $185-199$

\section{INTRODUCTION}

Aircraft noise affects millions of people in Europe (MPD, 2007). The population exposed to aircraft noise is likely to increase in future (MPD, 2007), because air traffic as well as the population around airports will continue to increase rather than decrease. Aircraft noise has various aspects (Bolt, 1953). It may annoy people (e.g., Miedema and Vos, 1998; Brink et al., 2008), disturb them in their sleep (Pearsons et al., 1995; Basner et al., 2006; Michaud et al., 2007), and have deleterious health effects such as hypertension (Jarup et al., 2008), besides economical consequences (e.g., for land use planning). It, therefore, often causes intensive political (e.g., Kroesen and Bröer, 2009) and scientific debates, necessitating its accurate assessment. However, while much research focuses on the effects of aircraft noise, studies on aircraft noise modeling are rare.

The characteristics of air traffic may vary during the time of day. The topic is not the changes in runway usage that will be accounted for in noise calculations anyway but more subtle variations. For instance, long range flights with poor climb performance due to large take-off weight may start preferably in the evening/beginning of the night. Or there may be operational constraints for noise mitigation leading to the non-use of specific corridors during night time. The present paper investigates

\footnotetext{
${ }^{a)}$ Portions of this work were presented in "Aircraft noise calculations for relevant periods of day using a complete set of radar data," Proceedings of NAG/DAGA 2009, International Conference on Acoustics, including the 35th German Annual Conference on Acoustics (DAGA), Rotterdam, The Netherlands, March 2009.

b) Author to whom correspondence should be addressed. Electronic mail: beat.schaeffer@empa.ch

${ }^{c}$ Present address: Amt für Natur und Umwelt Graubünden, Gürtelstrasse 89, 7000 Chur, Switzerland.
}

these effects on noise contours by comparing a high precision calculation using all available radar data and considering the time of day of the flights with a calculation using averaged subsets of flight geometries. (While other factors such as atmospheric effects or sound source conditions may also affect the results, they are not the focus of this paper.)

The dependence of noise contours on the time of day arises especially with the requirements of Swiss legislation (Noise Abatement Ordinance, NAO, 1986), which differentiates four time periods within the $24 \mathrm{~h}$ of a day: One for the day lasting for $16 \mathrm{~h}$ and three separate night periods, each lasting for $1 \mathrm{~h}$ (plus a flight curfew of $5 \mathrm{~h}$ ). A similar dependence of noise contours on the time of day may also arise for the day-evening-night level $L_{\mathrm{den}}$ used in the European Union or for the day-night level $L_{\mathrm{dn}}$ used in the United States.

The large areas covered by aircraft noise (MPD, 2007) make it impractical to assess the noise contours with measurements. Instead, aircraft noise contours are determined with model calculations, as explicitly required also by various legislations (e.g., NAO, 1986; 1. FlugLSV, 2008; or FAA regulations in the United States such as 14 CFR Part 150: CFR, 1984). As the model results have important consequences for land use planning and payments of compensation, the model calculations need to be highly accurate. The question arises as to what degree of detail one needs to account for in the air traffic, particularly, changes with time of day. This study focuses on the question of how to handle the variation in input parameters in calculation projects. This applies to any acoustic model used for the calculations. As reviewed in detail by Bütikofer (2007), different generations of aircraft noise models exist with various levels of sophistication, such as the former AzB (Der Bundesminister des Inneren, 1975), the current AzB (1. FlugLSV, 2008), INM 
(Gulding et al., 1999; Olmstead et al., 2001), Doc.29 3rd Edition (ECAC, 2005a,b), RNM (Page et al., 2001), or Flula2 (Pietrzko and Hofmann, 1988; Empa, 2010). The present study was made with the simulation model FLULA2 which allows for very detailed air traffic modeling.

Any aircraft noise calculation is split in two major parts: (1) the concentration of the real world situation with all aircraft movements into a few input parameters and (2) the acoustic calculations based on these input data. The set of input parameters is often called "scenario." It consists of the indication of "When flew? How many aircraft? Of what aircraft/engine type? Where in the air?," which translates into tracks, climb, and thrust profiles (or, alternatively, flight paths defined from radar data), aircraft grouping, and number of movements (Bütikofer, 2007). Data collection and processing are time-consuming tasks and depend on the complexity of the scenario, which is determined by the required level of accuracy: For surveys, a coarse description is appropriate, whereas for precision calculations, the scenario is rather complex and may take into account the variation in air traffic in the various time periods of the day.

The acoustic calculations for one specific flight path of a specific aircraft type may take a relatively long time, especially with simulation models also taking into account shielding by the topography. One strategy to keep total calculation times down to hours or days is to calculate first the sound immission (usually the A-weighted $L_{\mathrm{AE}}$ ) on all receiver points (arranged in a grid) for one aircraft movement of a specific aircraft/engine type along a specific flight path. This result is called "footprint." With footprints available, it is then relatively simple to add up energetically all the specific footprints, weighted with the number of corresponding movements, and finally to calculate the noise contours. It is straightforward to account for the changes in air traffic with the time of day by considering the number of movements in the various time slots. However, if also variations in flight performance or in the usage of flight corridors occur, then the use of "typical" footprints may no longer be appropriate, but more specific footprints may have to be calculated to reflect these changes.

How are footprints calculated? There are two main approaches: averaging of flight geometries and averaging of the acoustic immission (Bütikofer and Thomann, 2001). When using averaged flight geometries, a set of statistically representative idealized flight paths are usually generated from flight tracks (projections of the flight paths to the horizontal plane) and flight profiles (altitude, speed, and thrust as a function of the flown distance). The flight tracks are usually obtained from nominal track descriptions of airports (e.g., aeronautical information publications) and possibly furnished with some side tracks to account for the horizontal dispersion in the flight paths. Flight profiles may be estimated from aircraft performance data, as implemented in INM (Gulding et al., 1999; Olmstead et al., 2001) or Doc.29 3rd Edition (ECAC, 2005a,b). This, however, suffers from the affliction of considerable uncertainty and may cause large errors in the resulting sound levels (Clemente et al., 2005). A further shortcoming of such flight profiles is that they represent arithmetic averages while sound levels add up energetically, which may further affect predicted sound levels (Bütikofer et al., 1999).
The calculation of footprints using averaging of the acoustic immission works like a sound level meter. Usually based on individual radar recordings from air traffic control, many individual aircraft movements (of one aircraft/engine type on a specified air route) are calculated separately, their noise immission levels are summed up energetically in the grid points, and finally, the total noise immission is rescaled to one flight operation to obtain the footprint. This method has been used at the authors' institution (Empa) for several years. To date, a subset of flight paths is randomly selected from all available radar data over 1 year, irrespective of the time of day the corresponding flights took place, to calculate mean footprints, representing averages resulting from the air traffic of a whole day on a yearly basis. Thus the flight path dispersion is more realistically considered, simulating the way that monitoring stations would record and average aircraft events. However, possible changes in flight paths over the $24 \mathrm{~h}$ of a day remain unaccounted for, although they may affect the resulting noise contours. Also, only using a subset of radar data instead of a complete dataset may further influence the results. Except for a recent conference paper (Schäffer et al., 2009; see below), the authors are not aware of other studies on such effects, and they may prove significant.

Taking into account the variation in flight paths over the $24 \mathrm{~h}$ of a day, as determined from a complete radar dataset over 1 year, will obviously enhance the accuracy of the noise contours. The question remains, however, for which situations the variation in flight paths may be sufficiently accounted by a subset of radar data and for which situations a complete radar dataset is necessary. To answer this question, calculations were performed exemplarily for two airports (Zurich and Geneva, Switzerland), using all of the available radar data over 1 year and accounting for variations in flight paths over the $24 \mathrm{~h}$ of a day. The results of this extended modeling approach were compared with results of the simpler approach which uses a subset of radar data only and does not consider their time-ofday-specific variations. Then the situations were determined for which the modeling approaches are equivalent.

Schäffer et al. (2009) presented, for Zurich airport, the effects on the model results of using a complete radar dataset and taking into account the variations in flight paths over the $24 \mathrm{~h}$ of a day. The current article extends the analysis to Geneva airport. Further, the effects of using a complete radar dataset (instead of only a subset) and accounting for the variations in flight paths over the $24 \mathrm{~h}$ of a day are separated. For the present paper, the authors also studied possible legal consequences and the potential to reproduce monitoring measurements in more detail. Finally, they determined the situations for which the modeling approaches are equivalent. The additional insights allow for more comprehensive discussion and conclusions.

\section{METHODS}

\section{A. Aircraft noise modeling}

\section{Data processing and acoustic model}

The inputs provided by the airports consist of radar data from air traffic control of all the flights over 1 year, and lists 
of the movements. Data processing comprises identifying each aircraft by its tail number and generating the statistics of movements per aircraft type (or aircraft group), air route, and period of day. Thereafter, radar data are inspected for physically plausible aircraft movements and extended to the runway. Finally, the acoustic calculations are made with the simulation program FLULA2. The model, its principal premises and the underlying acoustic data base are described in detail by Pietrzko and Hofmann (1988), Krebs et al. (2004), and Empa (2010). In short, Flula2 considers (1) the sound source data (source intensity and directivity patterns) of individual aircraft types, (2) the statistics of movements, (3) the detailed flight geometries, and (4) the topography. For this study, three modeling approaches were realized to account for changes in air traffic with time of day, as discussed in the next section.

\section{Modeling approaches to account for changes in air traffic with time of day}

a. Calculation of averaged footprints based on a subset of flight geometries (CAS). This is the standard way of operation used in FLULA2 to calculate aircraft noise based on radar data. In this approach, FLULA 2 randomly selects a subset of up to 100 flight paths per aircraft type and air route from the complete radar dataset over 1 year, irrespective of the time of day the corresponding flights occurred. If less than 100 flights took place for a given aircraft type on a defined air route, all of them are selected, while exactly 100 flight paths are selected where more are available. For each aircraft type/air route combination, FLULA2 calculates the mean $L_{\mathrm{AE}}$ to determine the footprints. Their determination is referred to as "footprint-calculation" in the following account. The resulting footprints represent yearly averages over the $24 \mathrm{~h}$ of a day.

b. Calculation of period-of-day-specific footprints based on a subset of flight geometries (CPS). In order to investigate the effect of accounting for time-of-day-specific changes in the flight geometries, a random subset of up to 100 flight paths per aircraft type and air route is still used, while now the time of day the corresponding flights occurred is taken into account by selecting all flight paths belonging to the respective periods of day, and performing separate footprint-calculations for each of these periods. Thus one obtains period-of-day-specific footprints, i.e., one footprint per aircraft type, air route, and period of day. In this study exactly the same subset of flight paths was used for the CAS and CPS approach. The CPS approach was performed for Zurich airport only.

c. Calculation of period-of-day-specific footprints based on a complete set of flight geometries (CPC). In order to investigate also the effect of using the complete radar dataset instead of only a subset, time-of-day-specific footprints are calculated as with CPS but using all available flight geometries over 1 year's flight operation. Thus, the "real" flight dispersion is exactly accounted for instead of being approximated by a statistical subset. As radar data cover only about $95 \%$ of all flights, the footprints are still scaled to one movement.

Once the footprints are calculated with one of the three approaches, they are weighted with the statistics of movements to obtain period-of-day-specific noise contours. Thus, differences in air traffic between different periods of day on a yearly average are considered in the CAS approach by means of weighting the footprints only. In contrast, the CPS and CPC approaches consider operational variation also in the footprint-calculations (period-of-day-specific flight geometries), in addition to weighting the footprints. [Note that while CAS, CPS, and CPC are strictly defined in this study, there are other options to define CAS and CPS. Schäffer et al. (2009) referred to CAS as "statistical choice calculation (SCC)" and to CPC as "complete time-of-day-specific calculation (CTC)," while they did not include CPS in their study.]

\section{B. The scenarios for the model calculations}

\section{Large and small aircraft}

Swiss legislation requires separate calculations for the sound exposure of "small" (maximum take-off weight $\leq 8618 \mathrm{~kg})$ and "large" aircraft $(>8618 \mathrm{~kg}$ ) during the day and of large aircraft during the night (NAO, 1986). (All movements of small aircraft are attributed to the day period.) Discriminating between large and small aircraft is meaningful also with respect to modeling. Small aircraft usually do not have or use transponders, and thus radar data are often missing, requiring the use of idealized flight paths, which is not the focus of this paper. In the case of Zurich and Geneva airports, the noise of small aircraft is much smaller than the one of large aircraft, and the calculations were made for the latter category only.

\section{Airports, air traffic, and performance}

The model calculations were made exemplarily for Zurich and Geneva airports. These two airports have very disparate flight regimes. While Zurich airport has a complex runway system with various air traffic directions, Geneva airport has a single runway, and its air traffic is mostly oriented north-east/south-west accordingly (cf. Fig. 1).

a. Zurich airport. For Zurich airport $\left(47^{\circ} 27^{\prime} 30^{\prime \prime} \mathrm{N}\right.$, $8^{\circ} 32^{\prime} 53^{\prime \prime} \mathrm{E}$ ), the model calculations (CAS, CPS, and CPC) were performed for the year 2006 with 235120 movements of large aircraft (Table I). Figure 1(a) shows the runway system and the corresponding air routes. The 14 departure routes represent an aggregation of several standard instrumental departures, and the four approach routes are based on instrumental landing systems. By grouping, i.e., substitution of aircraft with missing acoustical data by reference types of similar known characteristics, the number of aircraft types was reduced to a total of 51. (The grouping is based exclusively on acoustical criterions. The flight paths and resulting footprints of certain reference types may, therefore, contain a fraction of small aircraft. Discrimination of large and small aircraft by means of the maximum take-off weight is 


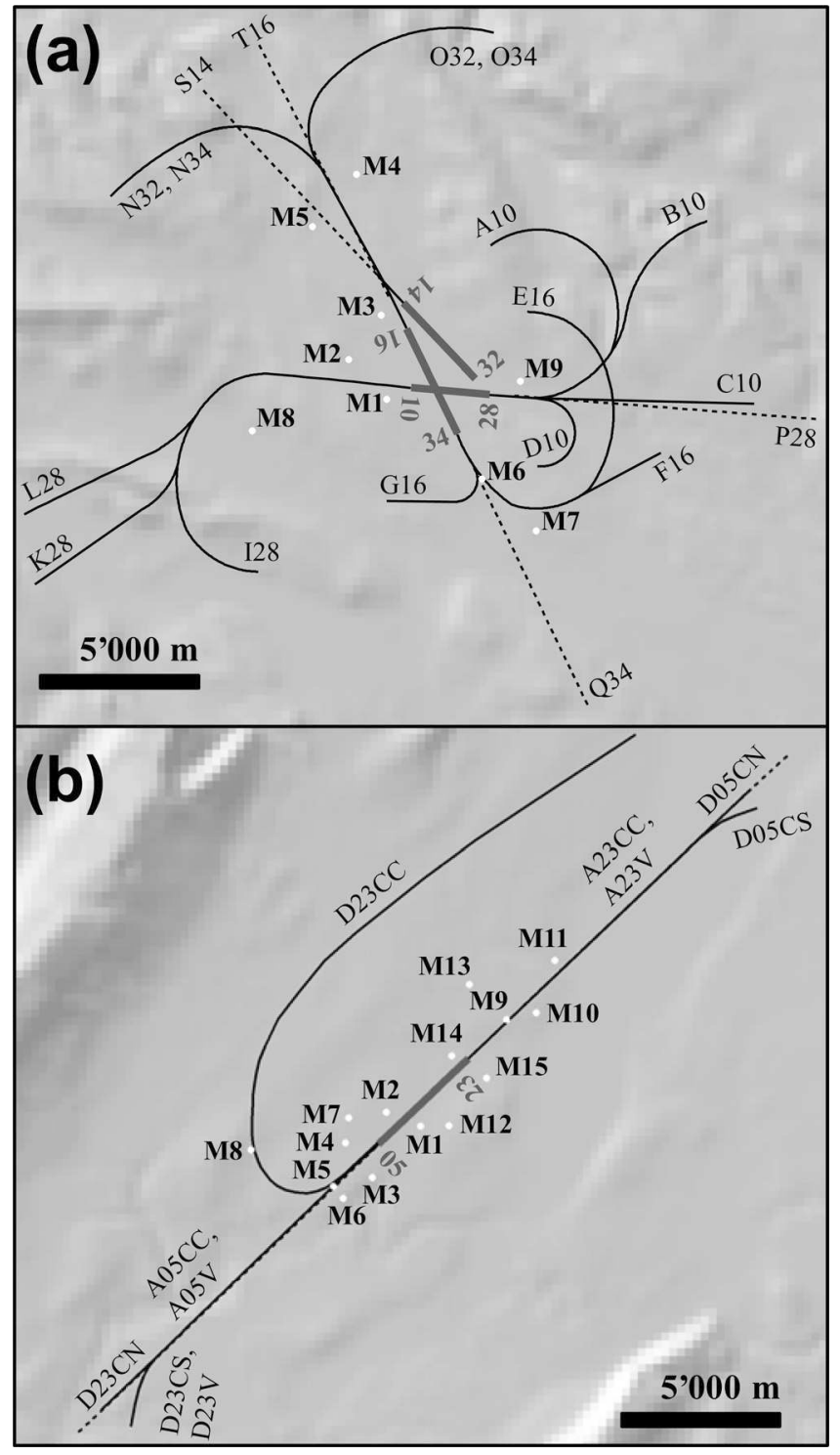

FIG. 1. Runway systems (gray), the schematic air routes (departure, solid; approach, dashed), and the locations of the monitoring stations. Top (a): Zurich airport with three (two directional) runways, 14 departure routes and 4 approach routes, and monitoring stations M1 to M9. Bottom (b): Geneva airport with one (two directional) runway, 6 departure routes and 4 approach routes, and monitoring stations M1 to M15. Background: Topography taken into account in the calculations.

effected during weighting of the footprints with the statistics of movements.) Different power settings were taken into account by using sound directivity patterns for maximum power and derated (flex) power for departures where the actual take-off weight was greater than and less than/equal to, respectively, $85 \%$ of the maximum take-off weight (Krebs et al., 2004).

b. Geneva airport. For Geneva airport $\left(46^{\circ} 14^{\prime} 18^{\prime \prime} \mathrm{N}\right.$, $6^{\circ} 6^{\prime} 34^{\prime \prime} \mathrm{E}$ ), the model calculations (CAS and CPC) were performed for the year 2008 with 159817 movements of large aircraft (Table I). The runway system and air routes are displayed in Fig. 1(b). In total, six departure routes (including one visual departure route, $\mathrm{D} 23 \mathrm{~V}$ ), four approach routes (including two visual approach routes, A05V and A23V), and (after grouping) 55 aircraft types were modeled. Different power settings were taken into account as for Zurich airport.

\section{Time periods and noise metrics}

The model calculations were performed according to Swiss legislation (NAO, 1986). For CAS, one footprint-calculation was performed (see above), while with CPS and CPC, four separate footprint-calculations were performed for the required time periods, namely for the day (06-22 h), and the first (22-23 h), second (23-24 h), and last hour of the night $(05-06 \mathrm{~h}$ ), with flights from 00 to $05 \mathrm{~h}$ assigned to the second hour of the night (NAO, 1986). As there is a flight curfew in Switzerland from 00 to $06 \mathrm{~h}$ (i.e., $1 \mathrm{~h}$ longer than in the rating sound concept of NAO, 1986, see above) with only a few emergency flights taking place, the noise of the last hour of the night $\left(L_{\text {Aeq,n3 }}\right)$ is negligible and not discussed in the following. Based on the footprints obtained with the modeling approaches, the following equivalent continuous sound levels $\left(L_{\text {Aeq }}\right)$ were calculated as prescribed by NAO (1986). [Note that the NAO (1986) defines rating sound levels (see BAFU, 2002, for details), which in the case of large aircraft are equal to the $L_{\text {Aeq. }}$ ]

- $L_{\text {Aeq, } \mathrm{d}}$ : Noise of the traffic of large aircraft during the day from 06 to $22 \mathrm{~h}$ on a yearly average.

- $L_{\text {Aeq,n1 }}$ : Noise of the traffic of large aircraft during the first hour of the night from 22 to $23 \mathrm{~h}$ on a yearly average.

- $L_{\text {Aeq,n } 2}:$ Noise of the traffic of large aircraft during the second hour of the night from 23 to $24 \mathrm{~h}$ on a yearly average.

For Geneva airport, also the $L_{\mathrm{den}}$ was calculated for the traffic of large aircraft using CAS and CPC. While for CAS the same footprints as for $L_{\mathrm{Aeq}, \mathrm{d}}, L_{\mathrm{Aeq}, \mathrm{n} 1}$, and $L_{\mathrm{Aeq}, \mathrm{n} 2}$ were used, three additional footprint-calculations had to be performed for CPC, namely for the day (06-18 h), evening (18-22 h), and night (22-06 h). Based on the footprints, the

TABLE I. Number of movements of large aircraft (maximum take-off weight $>8618 \mathrm{~kg}$ ) per period of day according to NAO (1986) for Zurich airport in the year 2006 and for Geneva airport in the year 2008.

\begin{tabular}{lrrrrrrrr}
\hline \hline & \multicolumn{3}{c}{ Zurich airport, 2006 } & & \multicolumn{2}{c}{ Geneva airport, 2008 } \\
\cline { 2 - 3 } Period of day & Starts & Approaches & Total & & Starts & Approaches & Total \\
\hline Day (06-22 h) & 113473 & 113743 & 227216 & & 78505 & 72936 & 151441 \\
First hour of the night $(22-23 \mathrm{~h})$ & 2969 & 3425 & 6394 & 1089 & 4590 & 5679 \\
Second hour of the night $(23-05 \mathrm{~h})$ & 1115 & 393 & 1508 & 303 & 2388 & 2691 \\
Last hour of the night $(05-06 \mathrm{~h})$ & 1 & 1 & 2 & 2 & 4 & 6 \\
Total & 117558 & 117562 & 235120 & 79899 & 79918 & 159817 \\
\hline \hline
\end{tabular}


$L_{\text {Aeq }}$ of the three time periods was calculated (denoted as $L_{d}$, $L_{e}$, and $L_{n}$ in the following) and energetically summed up, adding $5 \mathrm{~dB}$ to $L_{e}$ and $10 \mathrm{~dB}$ to $L_{n}$ to obtain the $L_{\text {den }}$ (European Union, 2002). While the study focuses on the noise exposures according to NAO (1986), these results are discussed as well, because the $L_{\text {den }}$ is used in various studies (e.g., Miedema and Oudshoorn, 2001; Brink et al., 2008) and guidelines (European Union, 2002).

\section{Comparisons}

\section{Flight paths and resulting footprints}

The flight paths used for the footprint-calculations of CAS and CPC and the resulting footprints were compared for Zurich airport for selected aircraft types and air routes.

All other input data (sound source data, statistics of movements, and topography) are identical for the modeling approaches and are, therefore, not discussed in the following.

\section{Sound levels}

The sound levels $\left(L_{\mathrm{Aeq}, \mathrm{d}}, L_{\mathrm{Aeq}, \mathrm{n} 1}\right.$, and $L_{\mathrm{Aeq}, \mathrm{n} 2} ; L_{d}, L_{e}, L_{n}$, and $L_{\text {den }}$ ) obtained with the modeling approaches were compared cartographically, qualitatively by overlaying the noise contours, and quantitatively as differences in the sound levels.

In addition, the mean differences and standard deviations in the sound levels at the grid points were calculated as a function of the sound level in steps of $1 \mathrm{~dB}$, i.e., for classes of $1 \mathrm{~dB}$ width. The results show the differences between the modeling approaches at grid points in areas exposed to the respective sound levels. Only sound levels from 43 to $70 \mathrm{~dB}$ were taken into account, as sound exposures below $43 \mathrm{~dB}$ are not legally relevant (NAO, 1986), while those above 70 $\mathrm{dB}$ occur mostly within the premises of Zurich and Geneva airports and are, therefore, not of interest.

\section{Areas and persons above exposure limits}

In order to estimate possible legal consequences of the modeling approaches, the authors determined the size of the areas and number of affected persons where the exposure limits according to NAO (1986), i.e., planning values $<$ impact thresholds $<$ alarm values, are exceeded (see BAFU, 2002, for details). [As NAO, 1986, has the requirement to account also for the sound exposures of small aircraft during the day (see above), the authors estimated these by scaling existing calculations of previous years with the number of movements of the model years (Zurich: 25298 movements; Geneva: 30228 movements), and then added them energetically to the $L_{\text {Aeq, } d}$.] The exceedances of the exposure limits were determined separately for the individual sound levels according to NAO (1986) (noise of small aircraft alone, $L_{\text {Aeq,d }}$ including the noise of small aircraft, $L_{\text {Aeq,n1 }}, L_{\text {Aeq,n2, }}$, and $\left.L_{\text {Aeq,n3 }}\right)$ as well as for their envelopes, i.e., their set union. For the calculations the population census data of the year 2000 (Zurich airport), respectively, of 2008 (Geneva airport) were used.

\section{Comparison with monitoring data}

Finally, the sound levels obtained with the modeling approaches $\left(L_{\text {Aeq,d }}, L_{\text {Aeq,n } 1}\right.$, and $L_{\text {Aeq,n } 2} ; L_{d}, L_{e}, L_{n}$, and $\left.L_{\text {den }}\right)$ were compared with measurements of several monitoring stations in the vicinity of Zurich and Geneva airports (cf. Fig. 1) to determine which modeling approach represents measurements most precisely. Although only large aircraft are considered in the calculations, comparison is possible because the sound of small aircraft often lies below the detection limits of the monitoring stations. For the determination of the $L_{\mathrm{Aeq}}$, the monitoring stations take into account events only which are attributable to an aircraft fly-over. For Zurich airport, the trigger thresholds used to separate aircraft noise events from background noise lay-depending on the location-between 56 and $67 \mathrm{~dB}$. For Geneva airport, the trigger thresholds of monitoring stations 2-14 lay $5 \mathrm{~dB}$ above the background noise of the last $30 \mathrm{~s}$ preceding an event. Monitoring station 1 was discarded from the comparisons because its measurements were strongly biased by high levels of local background noise.

\section{When to use which modeling approach}

Based on the differences in the sound levels between CPC and CAS (cf. Sec. II C 2) the situations (i.e., where and when) were determined for which CPC and CAS yield equivalent results. Given the standard uncertainties of aircraft noise calculations of up to $\pm 1.0 \mathrm{~dB}$ (Thomann, 2007), the grid points were determined, where

$$
\Delta L=|L(\mathrm{CPC})-L(\mathrm{CAS})|<1 \mathrm{~dB},
$$

with $\Delta L$ being the absolute difference in the sound immission levels as determined by CPC $[L(\mathrm{CPC})]$ and CAS $[L(\mathrm{CAS})]$, and $L$ representing any sound level $\left(L_{\mathrm{Aeq}, \mathrm{d}}\right.$, $L_{\text {Aeq,n1 }}$, and $L_{\text {Aeq,n2 }} ; L_{d}, L_{e}, L_{n}$, and $\left.L_{\text {den }}\right)$. For these grid points, the modeling approaches are considered to be equivalent, i.e., complete radar dataset (CPC) data may be replaced by the subset (CAS), while for all other grid points (i.e., for $\Delta L \geq 1 \mathrm{~dB}$ ), CPC should be used. For the latter grid points the cumulative frequency distribution was calculated to determine the fractions of the areas with $\Delta L$ not fulfilling Eq. (1) as a function of the distance from the airports.

\section{Number of footprint-calculations}

The number of flight paths used to calculate the footprints is almost nine times larger for CPC than for CAS/CPS (Table II). Thereof, the fraction of small aircraft (see above) is $0 \%-3 \%$ (Zurich airport) and $0 \%-6 \%$ (Geneva airport), depending on the period of day. The number of calculated footprints increases in the order CAS $<$ CPS $<$ CPC.

In a few cases, there are missing flight paths of certain aircraft types on given air routes due to missing radar data, and substitution or neglect of the corresponding movements is necessary. This applies to all methods. However, with increasing number of footprint-calculations, respectively, with decreasing number of flight paths considered per footprint-calculation, the number of missing footprints increases, 
TABLE II. Time periods, number of considered flight paths, number of calculated footprints, and number of missing footprints/number of corresponding movements for the modeling approaches CAS, CPS, and CPC (see Nomenclature and text for definition and explanation) for Zurich and Geneva airports.

\begin{tabular}{|c|c|c|c|c|c|c|}
\hline Airport & $\begin{array}{l}\text { Calculation } \\
\text { according to }\end{array}$ & $\begin{array}{l}\text { Modeling } \\
\text { approach }\end{array}$ & Time periods & $\begin{array}{l}\text { Number of } \\
\text { flight paths }\end{array}$ & $\begin{array}{l}\text { Number of } \\
\text { footprints }\end{array}$ & $\begin{array}{l}\text { Number of missing footprints/ } \\
\text { Number of movements }\end{array}$ \\
\hline \multirow[t]{3}{*}{ Zurich } & \multirow[t]{3}{*}{ NAO (1986) } & CAS & $24 \mathrm{~h}$ & 27078 & 560 & $19 / 27$ \\
\hline & & CPS & Day, first, second, last hour of night & 27078 & 785 & $64 / 279$ \\
\hline & & $\mathrm{CPC}$ & Day, first, second, last hour of night & 235895 & 824 & $26 / 37$ \\
\hline \multirow[t]{4}{*}{ Geneva } & \multirow[t]{2}{*}{ NAO (1986) } & CAS & $24 \mathrm{~h}$ & 18372 & 337 & $15 / 37$ \\
\hline & & $\mathrm{CPC}$ & Day, first, second, last hour of night & 162869 & 632 & $26 / 51$ \\
\hline & \multirow[t]{2}{*}{$L_{\mathrm{den}}$} & CAS & $24 \mathrm{~h}$ & 18372 & 337 & $16 / 37$ \\
\hline & & $\mathrm{CPC}$ & Day, evening, night & 162869 & 788 & $28 / 73$ \\
\hline
\end{tabular}

namely in the order CAS $<$ CPC $<$ CPS (Table II). A large number of missing footprints increases the uncertainty of the calculations. While for CPC the corresponding additional uncertainty is negligible, it is not for CPS.

\section{RESULTS}

\section{A. Flight paths and resulting footprints}

Figures 2 and 3 show, exemplarily for two aircraft types and air routes of Zurich airport, the flight paths taken into account in the footprint-calculations of CAS and CPC. The subset used for CPS corresponds to a mix of the sets used by CAS (same subset of flight paths) and CPC (same periods of day taken into account) (not shown).

Generally, the random selection of flight paths for a single footprint-calculation (CAS) adequately represents the dispersion of the flight paths of the day, and the resulting footprints of CAS and CPC are similar [cf. Figs. 2(a) and 3(a)]. The same is true also for night, given that the dispersion of the flight paths corresponds to that of the day. This applies, e.g., to the approaches after the aircraft line up, because the flight dispersion (horizontal and vertical) is small and time invariable due to the instrumental landing system. In contrast, where the flight paths differ from those of the day, or where only few flight paths exist, the random selection of flight paths may not adequately represent the dispersion of the flight paths of the night, and the resulting footprints of CAS and CPC will differ. Figure 2 shows the situation where the vertical flight dispersion remains time invariable, while the horizontal dispersion strongly varies over the $24 \mathrm{~h}$ of a day due to changes in flight allocation to different standard instrumental departures. The fact that the Avro RJ100 did not turn east during the second hour of the night cannot be taken into account with CAS, and the resulting footprint is very inaccurate [Fig. 2(c)]. The same as for the flight tracks applies to the vertical dispersion of the flight paths (Fig. 3). Large differences are observed in the night even if the horizontal dispersion remains time invariable if heavy aircraft start for intercontinental flights, having smaller angles of climb than during the day, which may only be accounted for by CPC [Figs. 3(b) and 3(c)]. As the flight paths concentrate within narrow corridors in the vicinity of airports but fan out further away, the differences between the footprints increase with distance from the airports (Figs. 2 and 3). In the next section, the effects of these differences on the resulting noise contours are discussed.

\section{B. Sound levels and noise contours}

Figures 4 and 5 compare the $L_{\mathrm{Aeq}, \mathrm{d}}, L_{\mathrm{Aeq}, \mathrm{n} 1}$, and $L_{\mathrm{Aeq}, \mathrm{n} 2}$ around Zurich and Geneva airports as determined by CPC and CAS. For both airports, large positive and negative differences occur locally, which increase with distance from the airports and also, more importantly, with distance from the center lines of frequented air routes (cf. Fig. 1 and further below) (i.e., with decreasing sound levels) as well as with the period of day (day $<$ first hour of the night $<$ second hour of the night) (Fig. 4). However, within the sound contours relevant for NAO (1986), i.e., for $L_{\mathrm{Aeq}, \mathrm{d}} \geq 53 \mathrm{~dB}, L_{\mathrm{Aeq}, \mathrm{n} 1} \geq 43$ $\mathrm{dB}$, and $L_{\text {Aeq,n2 }} \geq 43 \mathrm{~dB}$, differences remain small (mostly $<1 \mathrm{~dB}$ ). Only in the north-east of Geneva airport, larger differences of up to $2 \mathrm{~dB}$ occur during the night (Fig. 4) due to aircraft on air route $\mathrm{A} 23 \mathrm{CC}$ (cf. Fig. 1) lining up further to the north-east during the day than during the night (not shown). During the day, the mean differences in $L_{\mathrm{Aeq}, \mathrm{d}}$ per dB-class between CAS and CPC are negligible, adopting values of -0.01 to $+0.02 \mathrm{~dB}$ [Fig. 5(a), Table III]. While for $L_{\text {Aeq,n1 }}$ the differences of -0.32 to $+0.10 \mathrm{~dB}$ remain moderate, they get as large as -0.33 to $+0.24 \mathrm{~dB}$ for $L_{\text {Aeq,n2 }}$ [Figs. 5(b) and 5(c), Table III]. For Zurich airport, $L_{\mathrm{Aeq}, \mathrm{d}}, L_{\mathrm{Aeq}, \mathrm{n} 1}$, and $L_{\mathrm{Aeq}, \mathrm{n} 2}$ of CPC by trend are higher than those of CAS for sound levels relevant for NAO (1986) (Fig. 5). For Geneva airport, the same is observed for $L_{\mathrm{Aeq}, \mathrm{d}}$, and for $L_{\mathrm{Aeq}, \mathrm{n} 1}$ above $55 \mathrm{~dB}$, while the opposite is true for $L_{\mathrm{Aeq}, \mathrm{n} 1}$ and $L_{\mathrm{Aeq}, \mathrm{n} 2}$ below $55 \mathrm{~dB}$ (Fig. 5), due to the differences in the north-east.

Similar results as for $L_{\mathrm{Aeq}, \mathrm{d}}, L_{\mathrm{Aeq}, \mathrm{n} 1}$, and $L_{\mathrm{Aeq}, \mathrm{n} 2}$ also apply to $L_{d}, L_{e}$, and $L_{n}$ of Geneva airport. Large local differences occur which increase with distance from the airports/ air routes and with the period of day (day $<$ evening $<$ night). The differences in $L_{d}$ and $L_{\mathrm{Aeq}, \mathrm{d}}$ are very similar, while those of $L_{n}$ are smaller than those of $L_{\text {Aeq,n1 }}$ and $L_{\text {Aeq,n2 }}$ (not shown). Thus, the differences not only increase with the time of day, but also with decreasing length and thus decreasing number of flight paths within a time period, because the subset of radar data used in CAS becomes less representative. The differences between CPC and CAS in the resulting $L_{\mathrm{den}}$ per dB-class remain small $(-0.08$ to +0.02 $\mathrm{dB}$ between 43 and $70 \mathrm{~dB}$ ).

The period-of-day-specific footprint-calculation and the choice of all flight paths contributed to different degrees to the differences in $L_{\mathrm{Aeq}, \mathrm{n} 1}$ and $L_{\mathrm{Aeq}, \mathrm{n} 2}$ between CPC and CAS observed above, depending on the period of day. For $L_{\text {Aeq,n1 }}$, CPS yielded very similar results as $\mathrm{CPC}$, and the major 


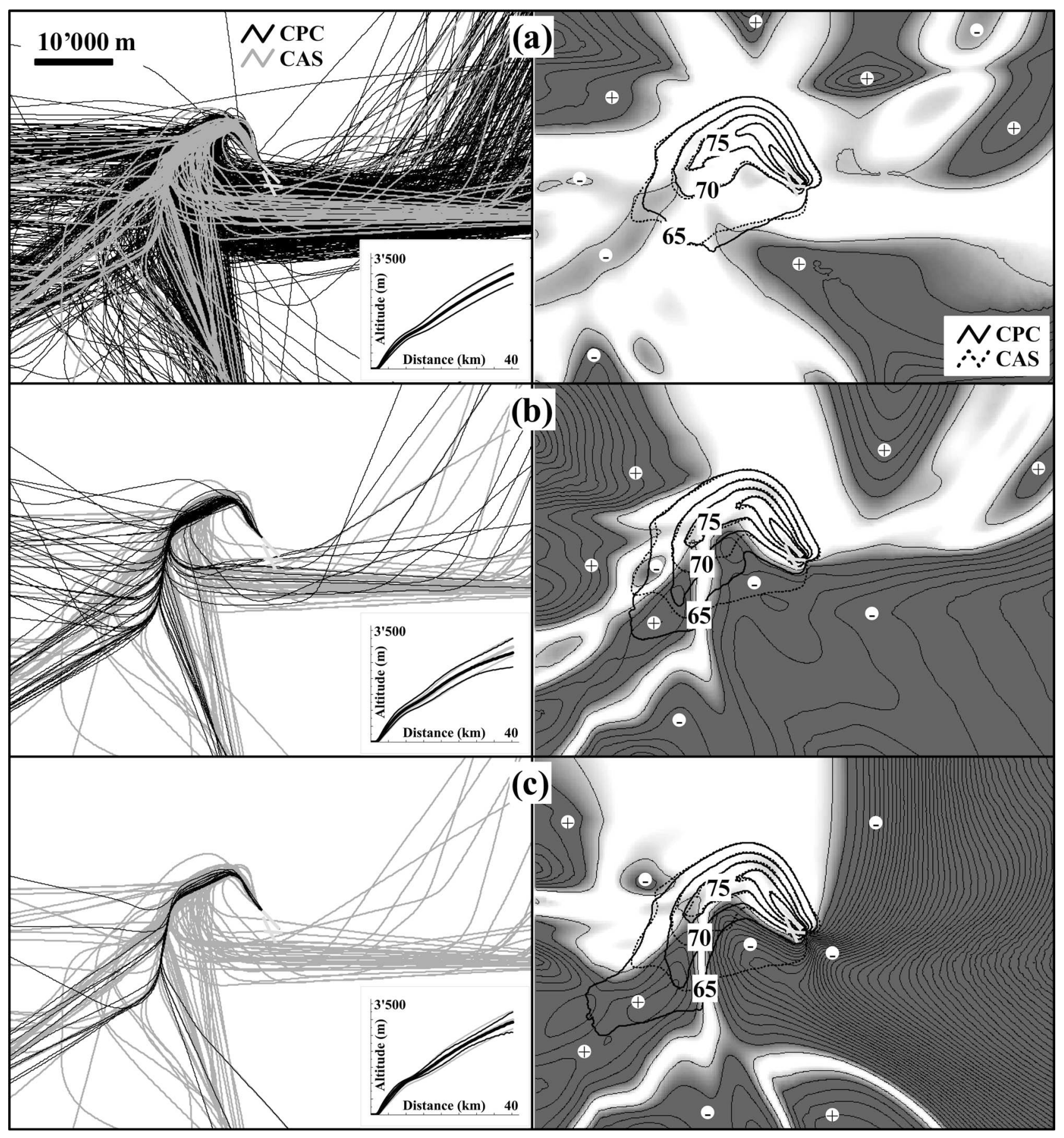

FIG. 2. Effects of the modeling approach (CAS and CPC; see Nomenclature and text for definition and explanation) on the footprint: variation in track usage (example for starts of Avro RJ100 on air route N32 of Zurich airport). Left side: Tracks and in the inserted figures the respective climb profiles (bold lines, mean profiles; thin lines, standard deviations). Right side: resulting footprints $\left(L_{\mathrm{AE}}\right.$, scaled to one movement) as well as differences (CPC - CAS; "+" indicates positive differences, "-" indicates negative differences) as shadings (white for absolute differences $\leq 0.5 \mathrm{~dB}$; increasing gray levels for $0.5 \mathrm{~dB}<$ absolute differences $\leq 2 \mathrm{~dB}$ ) and as thin solid lines (1 dB steps). Top (a) day (06-22 h), middle (b) first hour of the night (22-23 h), and bottom (c) second hour of the night $(23-24 \mathrm{~h})$.

differences occurred between CPS and CAS [Fig. 5(b), Table III]. Here, the use of all available flight paths did not further improve the results. In contrast, for $L_{\text {Aeq,n2 }}$ both the period-of-day-specific footprint-calculation and the choice of all flight paths equally contributed to the differences between CPC and CAS [Fig. 5(c), Table III]. Here, using all flight paths did enhance the accuracy of the results. CPC mostly yielded higher sound levels than CPS, particularly for $L_{\text {Aeq,d }}$ and $L_{\text {Aeq,n2 }}$ (Fig. 5). Using all flight paths in the calculations probably increased their overall horizontal and vertical dispersion, which in turn caused higher sound levels, as the $L_{\mathrm{AE}}$ of single flight events add up energetically.

Despite local areas of large differences (Fig. 4), the mean differences per sound level class between the calculations remained small for every period of day, compared to the standard deviations of up to $\pm 0.4 \mathrm{~dB}$ (Zurich airport) and $\pm 0.7 \mathrm{~dB}$ (Geneva airport) (Fig. 5) and, in particular, also to the standard uncertainties of aircraft noise 


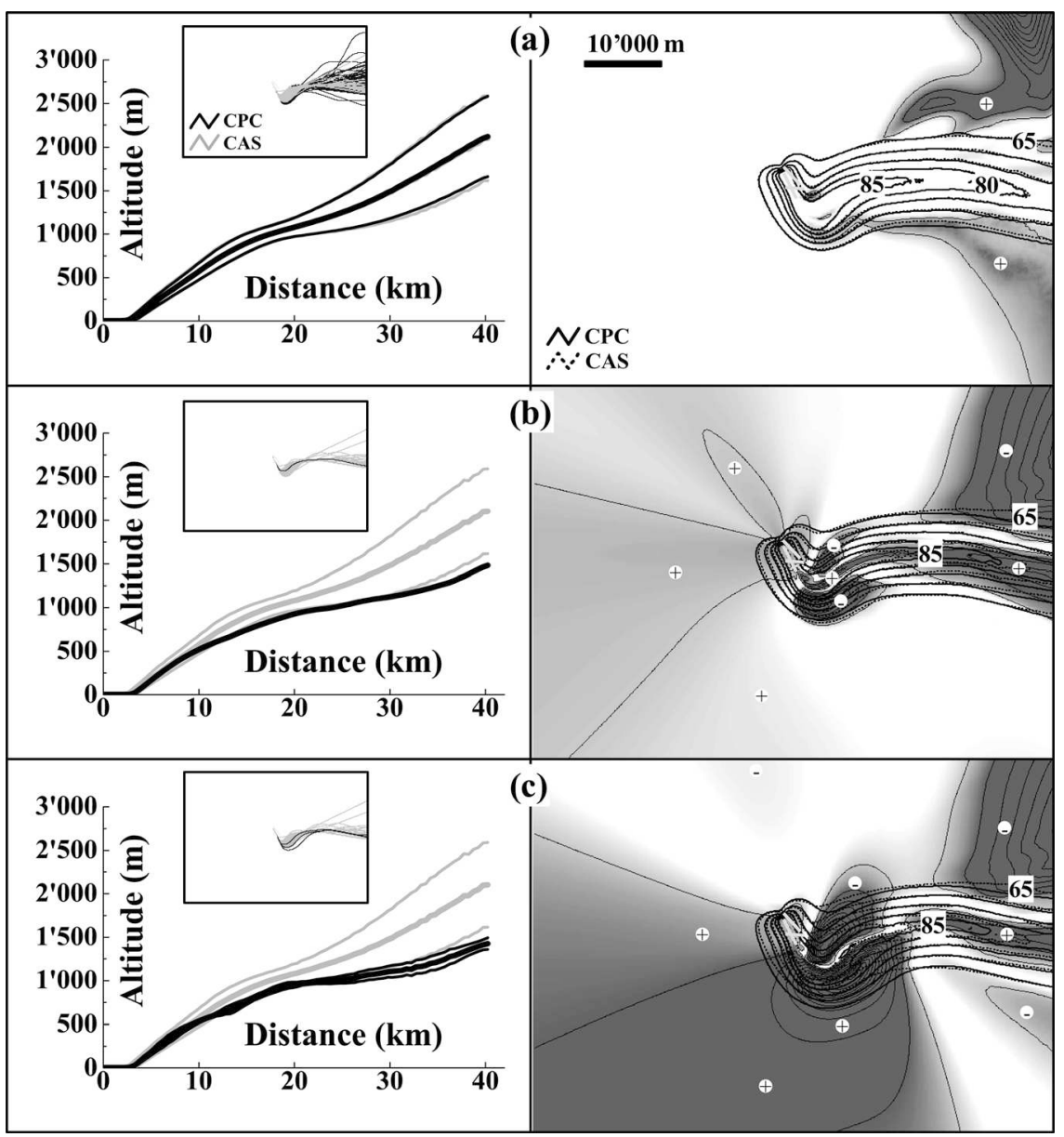

FIG. 3. Effects of the modeling approach (CAS and CPC; see Nomenclature and text for definition and explanation) on the footprint: variation in climb profiles (example for starts of Airbus A340-300 on air route F16 of Zurich airport). Left side: Climb profiles (bold lines, mean profiles; thin lines, standard deviations) and in the inserted figures the flight tracks. Right side: resulting footprints and differences between CPC and CAS (see header of Fig. 2, for details). Top (a) day (06-22 h), middle (b) first hour of the night (22-23 h), and bottom (c) second hour of the night (23-24 h).

calculations of $\pm 0.5 \mathrm{~dB}$ for the day and $\pm 1.0 \mathrm{~dB}$ for the night (Thomann, 2007). For $L_{\mathrm{Aeq}, \mathrm{d}}$, the mean differences per sound level class were of the same magnitude as, while for $L_{\text {Aeq,n1 }}$ and $L_{\text {Aeq,n2 }}$ they were larger than the differences attributable to the statistical choice of flight paths: An additional CAS calculation for Zurich airport based on a different subset of flight paths revealed that the mean differences per $\mathrm{dB}$-class between two CAS calculations ranged from -0.02 to $+0.01 \mathrm{~dB}$ for $L_{\mathrm{Aeq}, \mathrm{d}}$, from 0 to $+0.07 \mathrm{~dB}$ for $L_{\mathrm{Aeq}, \mathrm{n} 1}$, and from +0.01 to $+0.16 \mathrm{~dB}$ for $L_{\mathrm{Aeq}, \mathrm{n} 2}$.

Interestingly, areas of large sound level differences (positive or negative) occur at approximately the same locations for all three periods of day (Fig. 4) and partly coincide with landscape formations such as mountains (cf. Fig. 1). However, scatter plots of these differences vs ground level elevation revealed that there was great scatter and no close, if any, relation between the data (not shown). The set of flight paths used in the calculations is thus much more important for the resulting differences.

Figure 4 reveals large local differences of linear shape in the west and south-east of Zurich airport. These differences are caused by individual short flight paths, e.g., of aircraft aiming for a close air field, which were tracked a short distance only by the radar system. Short flight paths by default are extrapolated linearly for the calculations. Where the last part of the flight paths progresses horizontally, this leads to inaccurate extrapolations closely following the ground. For Geneva airport, in contrast to Zurich airport, such flight paths were not extrapolated. The artifacts in the calculation of Zurich airport were not corrected because (1) the differences occur in areas only where the sound levels are well below the exposure limits of NAO (1986) and are, thus, irrelevant and (2) the differences show the advantage of accounting for all available radar data, as even single flight events, if exceptional, may strongly affect the resulting noise contours locally.

\section{Areas and number of persons above exposure limits}

As expected from the differences between the $L_{\text {Aeq }}$ (see Sec. III B), the differences between CPC and CAS in areas with relevant individual sound exposures exceeding the exposure limits of NAO (1986) increased in the order day $<$ first hour of the night $<$ second hour of the night for both, Zurich and Geneva airport, and the results obtained with CPS tended to be closer to CPC than for CAS (not shown). For the number of persons within these areas, similar trends were observed, although they were less clear, as not only the areas but also the location of the sound contours with respect to populated areas plays a role.

The areas of the resulting envelopes of Zurich airport determined with CPC differed by less than $1 \%$ from those obtained with CAS, while for Geneva airport differences became as large as $3.5 \%$ (Table IV). The corresponding number of persons was up to $2 \%$ larger for CPC than for CAS in the case of Zurich airport, while it differed less than $1 \%$ between CPC and CAS for Geneva airport (Table IV). According to literature, a variation in sound level of $1 \mathrm{~dB}$ will generate a change in the respective areas of the noise 


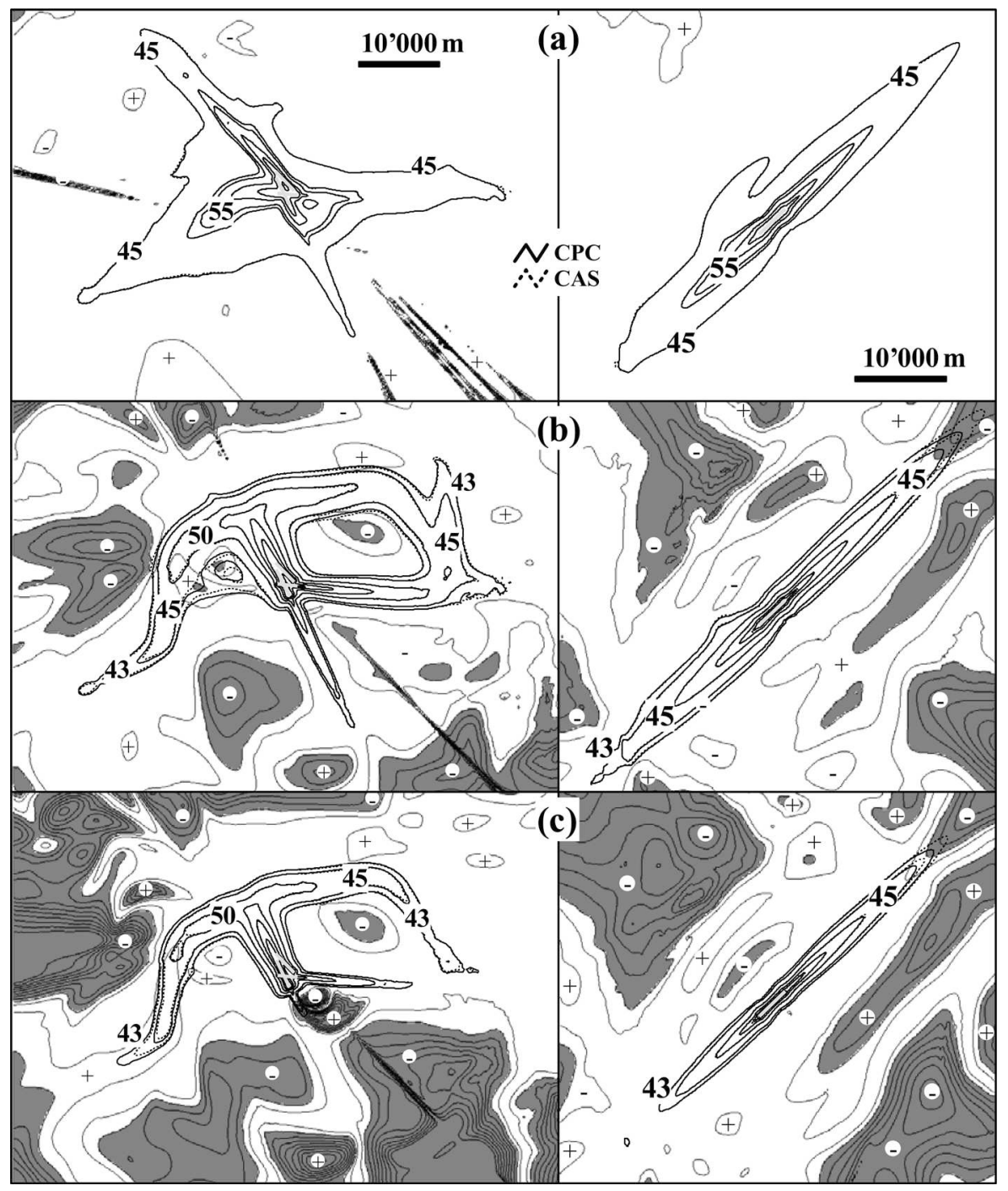

FIG. 4. Effects of the modeling approach (CAS and CPC; see Nomenclature and text for definition and explanation) on the noise contours for the complete air traffic over 1 year for large aircraft. Left side: Zurich airport, right side: Geneva airport. Top (a) day $\left(L_{\text {Aeq,d }}, 06-22 \mathrm{~h}\right)$, middle (b) first hour of the night $\left(L_{\text {Aeq,n } 1}, 22-23 \mathrm{~h}\right)$, and bottom (c) second hour of the night $\left(L_{\text {Aeq,n2 } 2}, 23-24 \mathrm{~h}\right)$. Each picture shows the noise contours calculated with CPC and-where a difference is visible-those calculated with CAS. Further, the differences CPC - CAS ("+" indicates positive differences, "-" indicates negative differences) are shown as shadings [white for absolute differences $\Delta L<1 \mathrm{~dB}$ according to Eq. (1); gray for $\Delta L \geq 1 \mathrm{~dB}$ ] and as thin solid lines ( $0.5 \mathrm{~dB}$ steps).

contours of $17 \%-22 \%$ (Isermann et al., 1989), and in the number of persons of 20\%-30\% (Empa, unpublished report No. 427733-1). Given the standard uncertainties of aircraft noise calculations $[ \pm 0.5 \mathrm{~dB}$ (day) and $\pm 1.0 \mathrm{~dB}$ (night), see Sec. III B], the standard uncertainties of the areas where exposure limits are exceeded add up to approximately $\pm 10 \%$ (day) to $\pm 20 \%$ (night), and those of the number of persons to $\pm 15 \%$ (day) to $\pm 30 \%$ (night). Compared to these uncertainties the differences between CPC and CAS are all very small.

\section{Comparison with monitoring data}

Figure 6 shows the scatter between calculated and measured $L_{\text {Aeq. }}$. The calculations mostly yield higher sound levels on a yearly average than the measurements. While the calculations represent the measurements very accurately for $L_{\mathrm{Aeq}}$ $\geq 55 \mathrm{~dB}$, the discrepancies between calculations and measurements increase with decreasing sound levels. This is mainly a consequence of incomplete recordings of the monitoring stations due to the trigger thresholds (Bütikofer and Thomann, 2009) and is probably in part also due to missing information on the actual take-off weight of aircraft, leading to inaccurate power settings in the calculations. In particular, the large differences for Zurich airport for $L_{\mathrm{Aeq}}<42 \mathrm{~dB}$ measured during the night (Fig. 6) origin from measurements of the monitoring stations 2,7 , and 8 which are located far away from the air routes most frequented in the night (N32, O32, N34, O34, and P28; cf. Fig. 1). However, with respect to legal requirements, calculations and measurements agree well for the day, i.e., for $L_{\text {Aeq,d }} \geq 53 \mathrm{~dB}$, and satisfactorily for the night, i.e., for $L_{\mathrm{Aeq}, \mathrm{n} 1}$ and $L_{\mathrm{Aeq}, \mathrm{n} 2} \geq 43 \mathrm{~dB}$ (Fig. 6). Correcting the measurements for bias (Bütikofer and Thomann, 2009) would further improve the agreement between calculations and measurements.

The differences between measurements and calculations are almost identical for CAS, CPC (Fig. 6) and CPS (not shown) in all three periods of day, i.e., for $L_{\mathrm{Aeq}, \mathrm{d}}, L_{\mathrm{Aeq}, \mathrm{n} 1}$, and

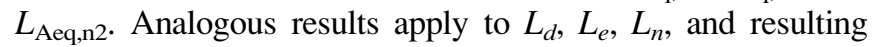
$L_{\text {den }}$ for Geneva airport, namely, a good agreement between calculations and measurements for sound levels above $55 \mathrm{~dB}$, increasing differences below, and the same agreement for CPC and CAS (not shown). Therefore, the modeling approaches CAS, CPS, and CPC are equivalent in their potential to represent monitoring measurements in the vicinity of airports.

\section{E. When to use which modeling approach}

Figure 4 shows the areas where, according to Eq. (1), $\mathrm{CPC}$ and CAS yield equivalent $(\Delta L<1 \mathrm{~dB})$ and different results $(\Delta L \geq 1 \mathrm{~dB})$. Neglecting the artifacts of linear shape 

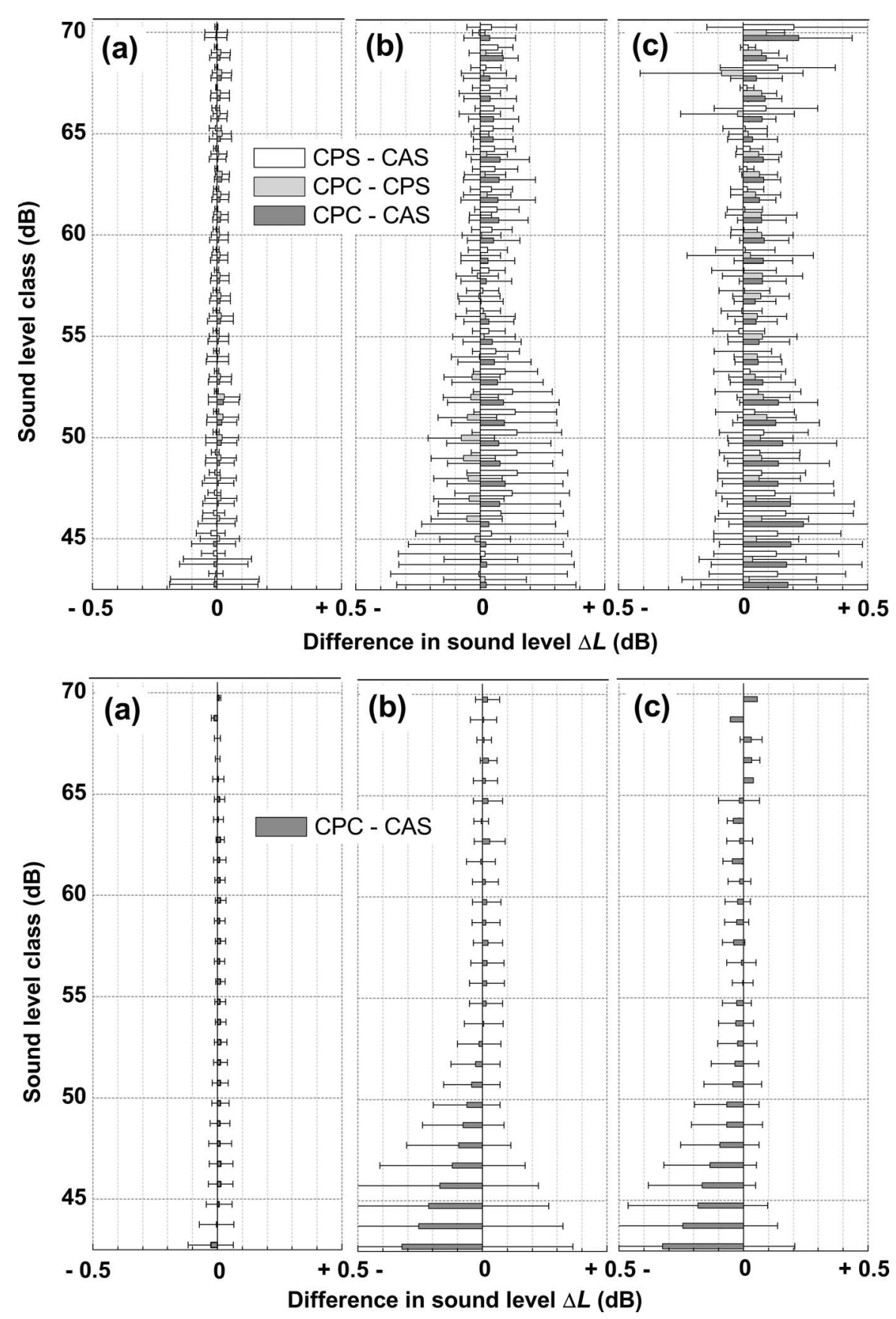

FIG. 5. Sound level differences between CPC, CPS, and CAS (see Nomenclature and text for definition and explanation) as a function of the sound level (bins of $1 \mathrm{~dB}$ width), in the $L_{\mathrm{Aeq}}$ of large aircraft during (a) day ( $L_{\text {Aeq,d }}, 06-22 \mathrm{~h}$ ), (b) first hour of the night $\left(L_{\text {Aeq,n1 }}, 22-23 \mathrm{~h}\right)$, and (c) second hour of the night $\left(L_{\text {Aeq,n2 } 2}, 23-24 \mathrm{~h}\right)$. Mean values (CPS - CAS, CPC - CPS, and CPC - CAS) plus standard difference bars. Top: Zurich airport, bottom: Geneva airport (CPC - CAS only). for Zurich airport (cf. Sec. III B), CPC and CAS yield equivalent results for the day and both airports (no or negligible areas with $\Delta L \geq 1 \mathrm{~dB}$ for $L_{\mathrm{Aeq}, \mathrm{d}}$ ), while for the night, large areas with $\Delta L \geq 1 \mathrm{~dB}$ occur (Fig. 4). As the cumulative fre- quency distributions of these areas show (Fig. 7), their fraction increases faster with distance (1) for $L_{\mathrm{Aeq}, \mathrm{n} 2}$ than for $L_{\text {Aeq,n1 }}$ and (2) for Geneva airport with its preferential orientation in air traffic [Fig. 1(b)] than for Zurich airport with its

TABLE III. Minimum $\left(\Delta_{\min }\right)$ and maximum $\left(\Delta_{\max }\right)$ differences of the sound level classes (i.e., minimum and maximum of the mean differences per sound level class in Fig. 5) and averaged differences of all sound level classes ( $\left.\Delta_{\text {mean }}\right)$ for $L_{\text {Aeq,d }}$ from 06 to $22 \mathrm{~h}\left(70 \mathrm{~dB} \geq L_{\text {Aeq,d }} \geq 53 \mathrm{~dB}\right), L_{\text {Aeq,n1 }}$ from 22 to $23 \mathrm{~h}$ ( $70 \mathrm{~dB} \geq L_{\mathrm{Aeq}, \mathrm{n} 1} \geq 43 \mathrm{~dB}$ ), and $L_{\mathrm{Aeq}, \mathrm{n} 2}$ from 23 to $24 \mathrm{~h}\left(70 \mathrm{~dB} \geq L_{\mathrm{Aeq}, \mathrm{n} 2} \geq 43 \mathrm{~dB}\right.$ ) between the modeling approaches CAS, CPS, and CPC (see Nomenclature and text for definition and explanation), for Zurich and Geneva airports.

\begin{tabular}{|c|c|c|c|c|c|c|c|c|c|c|}
\hline \multirow[b]{2}{*}{ Airport } & \multirow[b]{2}{*}{ Modeling approaches } & \multicolumn{3}{|c|}{$L_{\text {Aeq,d }}(\mathrm{dB})$} & \multicolumn{3}{|c|}{$L_{\text {Aeq,nl }}(\mathrm{dB})$} & \multicolumn{3}{|c|}{$L_{\mathrm{Aeq}, \mathrm{n} 2}(\mathrm{~dB})$} \\
\hline & & $\Delta_{\min }$ & $\Delta_{\max }$ & $\Delta_{\text {mean }}$ & $\Delta_{\min }$ & $\Delta_{\max }$ & $\Delta_{\text {mean }}$ & $\Delta_{\min }$ & $\Delta_{\max }$ & $\Delta_{\text {mean }}$ \\
\hline \multirow[t]{3}{*}{ Zurich } & CPS - CAS & -0.01 & 0 & 0 & -0.01 & +0.15 & +0.07 & -0.02 & +0.20 & +0.06 \\
\hline & $\mathrm{CPC}-\mathrm{CPS}$ & 0 & +0.02 & +0.01 & -0.08 & +0.03 & -0.01 & -0.09 & +0.09 & +0.05 \\
\hline & CPC - CAS & -0.01 & +0.02 & +0.01 & 0 & +0.10 & +0.06 & +0.04 & +0.24 & +0.11 \\
\hline Geneva & $\mathrm{CPC}-\mathrm{CAS}$ & -0.01 & +0.01 & +0.01 & -0.32 & +0.03 & -0.04 & -0.33 & +0.06 & -0.06 \\
\hline
\end{tabular}


TABLE IV. Areas and number of persons above exposure limits of NAO (1986) for Zurich and Geneva airports as determined by the modeling approaches CAS, CPS, and CPC (see Nomenclature and text for definition and explanation), and differences between the methods. Areas and persons determined for the envelopes, i.e., the set union of relevant sound levels (see text).

\begin{tabular}{|c|c|c|c|c|c|c|c|}
\hline \multirow[b]{2}{*}{ Airport } & \multirow[b]{2}{*}{ Method } & $\begin{array}{l}\text { Alarm } \\
\text { value }\end{array}$ & $\begin{array}{c}\text { Impact } \\
\text { threshold }\end{array}$ & $\begin{array}{c}\text { Planning } \\
\text { value }\end{array}$ & $\begin{array}{l}\text { Alarm } \\
\text { value }\end{array}$ & $\begin{array}{c}\text { Impact } \\
\text { threshold }\end{array}$ & $\begin{array}{c}\text { Planning } \\
\text { value }\end{array}$ \\
\hline & & \multicolumn{3}{|c|}{ Areas $\left(\mathrm{km}^{2}\right)$} & \multicolumn{3}{|c|}{ Persons $(-)$} \\
\hline \multirow[t]{3}{*}{ Zurich airport } & CAS & 58.5 & 404.5 & 574.1 & 2581 & 30597 & 77957 \\
\hline & CPS & 58.7 & 408.8 & 572.5 & 2581 & 30653 & 78841 \\
\hline & $\mathrm{CPC}$ & 58.7 & 407.2 & 571.9 & 2622 & 31203 & 78640 \\
\hline \multirow[t]{3}{*}{ Geneva airport } & CAS & 22.3 & 167.7 & 230.1 & 440 & 19373 & 47005 \\
\hline & $\mathrm{CPC}$ & 22.4 & 163.2 & 222.0 & 436 & 19412 & 46835 \\
\hline & & \multicolumn{6}{|c|}{ Differences $(\%)$} \\
\hline \multirow[t]{3}{*}{ Zurich airport } & CPS - CAS & +0.4 & +1.1 & -0.3 & +0.0 & +0.2 & +1.1 \\
\hline & $\mathrm{CPC}-\mathrm{CPS}$ & -0.1 & -0.4 & -0.1 & +1.6 & +1.8 & -0.3 \\
\hline & $\mathrm{CPC}-\mathrm{CAS}$ & +0.4 & +0.7 & -0.4 & +1.6 & +2.0 & +0.9 \\
\hline Geneva airport & CPC - CAS & +0.2 & -2.7 & -3.5 & -0.9 & +0.2 & -0.4 \\
\hline
\end{tabular}

various air traffic directions [Fig. 1(a)]. Within a perimeter for distances of up to at least $\sim 8 \mathrm{~km}, \mathrm{CPC}$ and CAS are equivalent for both airports and all periods of day $(\Delta L \geq 1$
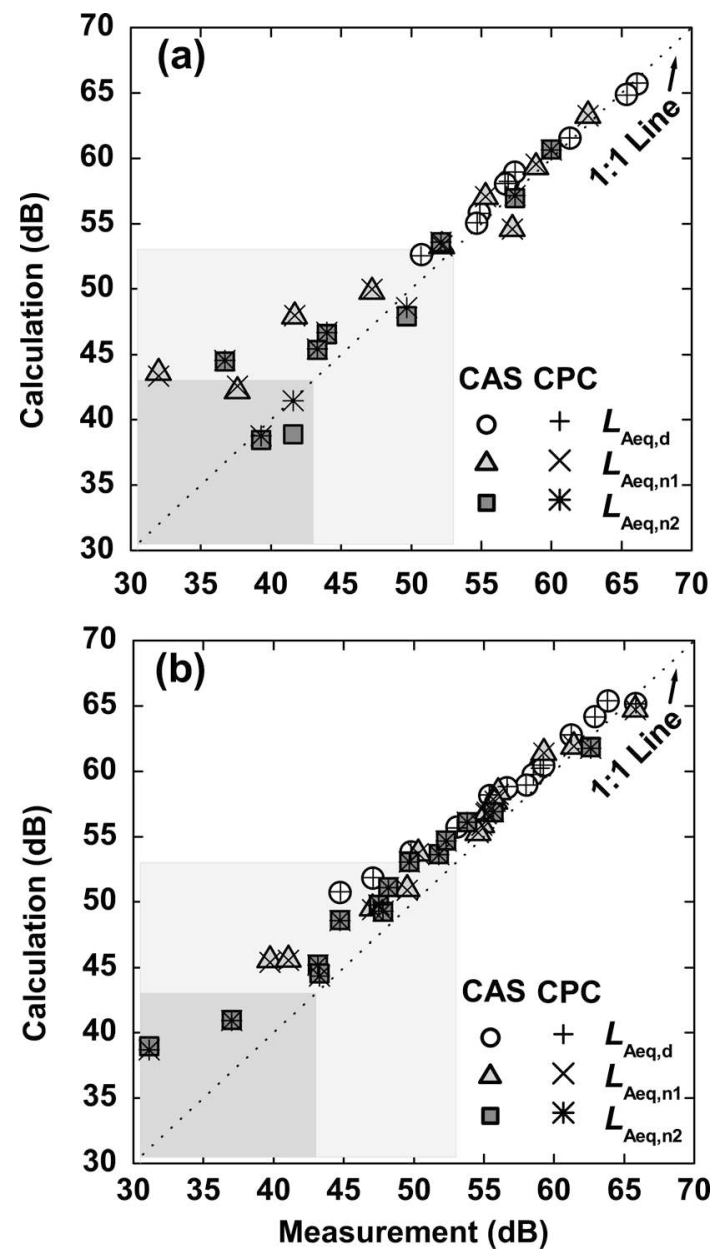

FIG. 6. Scatter diagrams of the $L_{\text {Aeq }}$ for the day $\left(L_{\text {Aeq, }}, 06-22 \mathrm{~h}\right)$, first hour of the night $\left(L_{\text {Aeq,n1 }}, 22-23 \mathrm{~h}\right)$ and second hour of the night $\left(L_{\text {Aeq,n2 }}, 23-24 \mathrm{~h}\right)$, as determined with monitoring measurements and by calculation with CPC and CAS (see Nomenclature and text for definition and explanation), for (a) Zurich airport and (b) Geneva airport. Light gray area: $L_{\mathrm{Aeq}} \leq 53 \mathrm{~dB}$; dark gray area: $L_{\mathrm{Aeq}} \leq 43 \mathrm{~dB}$.
$\mathrm{dB}$ for only $1 \%$ of the areas in the case of $\left.L_{\mathrm{Aeq}, \mathrm{n} 2}\right)$, while for double distances $(16-17 \mathrm{~km}), \Delta L \geq 1 \mathrm{~dB}$ occurs for up to $10 \%\left(L_{\mathrm{Aeq}, \mathrm{n} 2}\right)$ of the area already. Beyond, the areas strongly increase for both, $L_{\mathrm{Aeq}, \mathrm{n} 1}$ and $L_{\mathrm{Aeq}, \mathrm{n} 2}$, and CAS is not sufficiently accurate anymore. Similar results as for $L_{\mathrm{Aeq}, \mathrm{d}}$, $L_{\mathrm{Aeq}, \mathrm{n} 1}$, and $L_{\mathrm{Aeq}, \mathrm{n} 2}$ again apply to $L_{d}, L_{e}$, and $L_{n}$ of Geneva airport $\left(L_{d}, L_{e}\right.$, and $L_{\mathrm{den}}$ : no or negligible areas with $\Delta L \geq 1$ $\mathrm{dB} ; L_{n}: 1 \%$ and $10 \%$ of the areas with $\Delta L \geq 1 \mathrm{~dB}$ within perimeters for distances of $\sim 11$ and $17 \mathrm{~km}$, respectively).

\section{F. Extension to $1 \mathrm{~h}$ time slices}

To study in what detail one needs to account for the variation in air traffic over the $24 \mathrm{~h}$ of the day, an additional calculation was done for Zurich airport, using all available flight paths as with CPC, but performing 24 separate footprint-

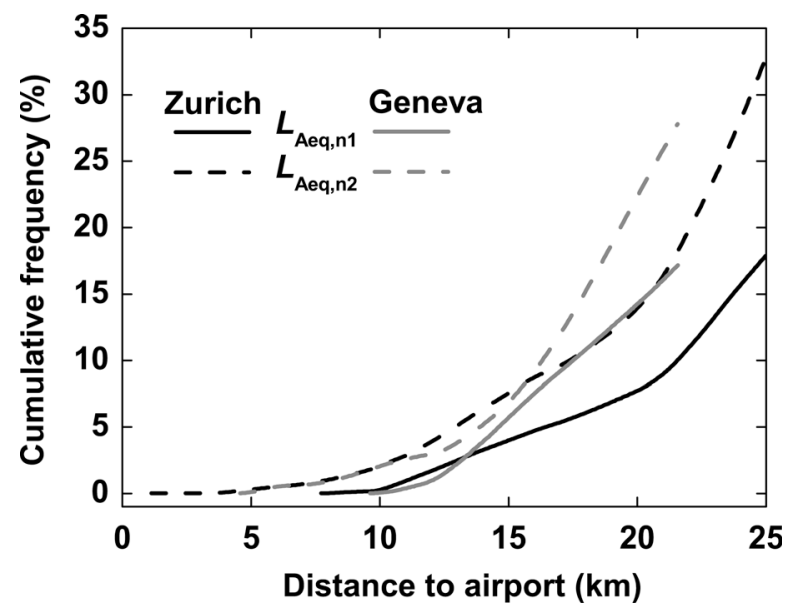

FIG. 7. Cumulative frequency distributions of the grid points with differences in the sound levels $\geq 1 \mathrm{~dB}$ (gray areas in Fig. 4) as a function of the distance to the airports (reference points: Zurich airport $47^{\circ} 27^{\prime} 30^{\prime \prime} \mathrm{N}$, $8^{\circ} 32^{\prime} 53^{\prime \prime} \mathrm{E}$; Geneva airport $\left.46^{\circ} 14^{\prime} 18^{\prime \prime} \mathrm{N}, 6^{\circ} 6^{\prime} 34^{\prime \prime} \mathrm{E}\right)$, for the first $\left(L_{\mathrm{Aeq}, \mathrm{n} 1}, 22\right.$ $23 \mathrm{~h})$ and second hours of the night $\left(L_{\mathrm{Aeq}, \mathrm{n} 2}, 23-24 \mathrm{~h}\right)$. The maximum distances (Zurich airport: $25.0 \mathrm{~km}$; Geneva airport: $21.6 \mathrm{~km}$ ) correspond to the radius of the largest circle completely contained within the rectangular calculation areas. The percentages refer to the fraction of the areas to the total areas of the largest circles. No/negligible areas with differences $\geq 1 \mathrm{~dB}$ for the day. 
calculations, one for every hour of the day, thus accounting for diurnal variations in flight paths in great detail.

The comparison between this calculation and CPC gave the following results. First, both calculations yield (by necessity) identical noise exposures where the same time periods are modeled, namely for the first and last hour of the night. Second, the calculated noise exposures of the remaining two time periods are almost identical (absolute differences per $\mathrm{dB}$-class $<0.015 \mathrm{~dB}$ for the day and $<0.001 \mathrm{~dB}$ for the second hour of the night). The (negligible) differences are attributable to additional missing footprints which had to be substituted in the case of the more detailed calculation, namely 93 footprints with 118 movements in total, compared to 26 footprints with 37 movements in the case of CPC (Table II). These numbers will increase with decreasing length of the time periods of the footprint-calculations. Third, over the time of day, no trends with respect to the magnitude of the differences were observed.

\section{DISCUSSION}

In this study, the noise contours around two airports were calculated based on a complete radar dataset over a whole year, accounting for their variation over the $24 \mathrm{~h}$ of a day. The authors are not aware of any other study accounting for such variation, in addition to the changes in the number of movements. Usually, the flight paths are represented by a limited number of idealized flight paths only (e.g., Clemente et al., 2005). Accounting for their variation with the time of day using idealized flight paths would be much more difficult, as sufficient information is usually lacking. The present approach therefore allows modeling the air traffic in great detail.

Three approaches (CAS, CPS, and CPC) to account for changes in air traffic were tested, and their effects on calculated time-of-day-specific noise contours were studied exemplarily for Zurich and Geneva airports. Despite the different flight regimes and shapes of the noise contours of the two airports, similar results were obtained for both airports, and also for different sound metrics ( $L_{\mathrm{Aeq}}$ according to Swiss legislation, as well as $\left.L_{\text {den }}\right)$. For the day, CAS, CPS, and CPC yielded almost identical $L_{\text {Aeq, }}$ while differences increased in the order day $<$ first hour of the night $<$ second hour of the night (respectively, day $<$ evening $<$ night). Thus, CAS may sufficiently account for the dispersion of the flight paths during the day. This was expected, as even CAS chooses 100 flight paths per aircraft type and air route where available, while only 4-5 flight paths per aircraft type may suffice to model the noise exposure (Bütikofer et al., 1999; Thomann, 2007). The increasing differences with the time of day are caused by the less representative selection of flight paths used for CAS. However, while CAS, CPS, and CPC may yield very disparate footprints (Figs. 2 and 3), these differences are leveled out largely in the summing up of the footprints to obtain the total sound exposures (Figs. 4 and 5), as the differences between footprints vary locally. With regard to legal requirements, CAS is therefore sufficiently accurate, and also, according to Eq. (1), CAS and CPC are equivalent for distances of at least $8 \mathrm{~km}$ from the airports for all periods of day (Fig. 7). Nevertheless, even small differences may still entail not least legal consequences (Table IV), particularly on a local scale affecting individual communities, and further away from the airport, large areas with differences $\geq 1 \mathrm{~dB}$ may occur (Fig. 7: 10\% of the total area within a perimeter for distances of $16-17 \mathrm{~km}$ for $L_{\mathrm{Aeq}, \mathrm{n} 2}$ ). The differences in sound levels may obviously be minimized by choosing a representative subset of radar data with CAS. The radar dataset contains information on the flight tracks and profiles (altitude and speed), and on their dispersion and variation over the $24 \mathrm{~h}$ of a day. Both the horizontal (Fig. 2) and vertical dispersion (Fig. 3) needs to be accurately accounted for. But also speed is important as it affects the total immission time and thus the $L_{\mathrm{AE}}$ of flyovers. Other characteristics such as thrust, in contrast, are not covered by radar data. They have to be estimated from other sources and may, therefore, not be improved by the choice of the radar dataset. These considerations apply also to other aircraft noise models.

The results on when to use which modeling approach [Eq. (1), Fig. 7] cannot be easily generalized for other airports. The differences not only depend on the absolute distance from an airport but rather on the number of annual movements, the distances flown by the aircraft (fanning out of flight tracks), and the distances of the receiver points to the center lines of the frequented air routes (cf. Fig. 4: small differences for $L_{\mathrm{Aeq}, \mathrm{n} 1}$ and $L_{\mathrm{Aeq}, \mathrm{n} 2}$ close to the major departure routes of the night, N32, N34, O32, and O34). To ascertain the situations for other airports for which CAS is sufficiently accurate, one may calculate the sound immission levels using both CAS and CPC to determine the areas satisfying Eq. (1). In subsequent calculations, CAS may be safely used for these areas, given that the flight regime did not substantially differ between calculated scenarios.

Both the period-of-day-specific footprint-calculations and using a complete radar dataset contributed to the differences between CPC and CAS. Thus only CPC by using all flight paths guarantees that any variation in the dispersion of flight paths is adequately modeled. The drawback of the detailed modeling of $\mathrm{CPC}$ is that it requires eight to nine times longer computational times than CAS ( 9-12 days for the footprint-calculations of CPC when using 20 processors on a computational cluster for Zurich airport), and that CPC is also more time consuming for the user due to increased data handling. Further, while the same footprints are used for every period of day in the case of CAS, CPC requires separate footprint-calculations for every period.

The methods (CAS, CPS, and CPC) are equivalent in their potential to represent monitoring measurements in the vicinity of airports. In remote areas, however, one may expect CPC to be more accurate than CAS and also CPS, as with increasing distance from the airport, the fanning out of the flight paths will be less accurately taken into account by CAS and CPS (cf. Figs. 2 and 3). As monitoring stations can only be operated where aircraft sound levels emerge clearly from background noise, i.e., close to airports, this hypothesis cannot be tested.

The results of this study may be relevant for various topics related to aircraft noise calculations. Studies on the 
effects of aircraft noise on people (annoyance, sleep disturbance, or medical effects, see Introduction section) heavily rely on acoustic data, and the reliability of results may be enhanced by more accurate aircraft noise calculations. Particularly, studies on the effects on sleep should be based on nighttime exposures determined with the CPC approach wherever possible, at least for areas further than a few kilometers away from an airport of comparable size, respectively, from frequented air routes. But also changed flight regimes on airports may be studied in great detail using CPC. For example, the effect of rerouting aircraft departures or approaches, which may efficiently reduce aircraft noise in populated areas (Makarewicz, 2004, 2010), may be realistically accounted for.

It has been shown that proper modeling of the input data improves the overall results, but that not always the most detailed modeling approach needs to be used. Further, using radar data instead of geometric input for the tracks and performance calculations for the climb profiles is another big step toward more realistic results. Radar data have the advantage that all factors influencing an aircraft's position such as head or side wind, climb performance, and weight are already accounted for. Finally, the performance of the acoustic calculation itself must be considered. Further improvement may be achieved through refinements of the model(s) and/or their database(s). First, lateral sound attenuation may be important. It comprises ground effects (e.g., Boulanger et al., 1997; Buret et al., 2006) as well as atmospheric effects (Gilbert et al., 1990; Embleton, 1996; Salomons, 2001). Scherebnyj and Hodgson (2007), for example, found that wind and atmospheric type strongly influence predicted sound levels of aircraft during run-ups, which may also affect sound levels of aircraft in flight. Lateral attenuation is also affected by aircraft configuration (Fleming et al., 2002). To date, these effects are usually only roughly accounted for by empirical formulas (Krebs and Thomann, 2009). Second, updating and refining existing sound source data for a larger number of reference types, and probably extending them to three-dimensional sound directivity (Krebs et al., 2003, 2006) may further improve the results. Third, including small-scale effects such as reflections in street canyons in urban environments would locally improve the model results (Ismail and Oldham, 2002), though at the expense of substantially increased computational times. Finally, a more detailed description of the source condition (e.g., power setting) reflecting different flight configurations would enhance model accuracy. Due to the lack of information, however, the latter effects are very difficult do model. These are possible topics for future research.

\section{v. CONCLUSIONS}

For the investigated scenarios, the modeling approaches CAS, CPS, and CPC on how to account for flight geometries yielded equivalent results for the long $(16 \mathrm{~h})$ time period of the day. For the shorter time periods of the evening and particularly night, differences showed up (Figs. 2-5, Table III), indicating that using average data (statistical sample of operations over the $24 \mathrm{~h}$ of a day as in CAS) represents the air traffic in such time slices less accurately. However, CAS and $\mathrm{CPC}$ were found to yield equivalent results within an area of at least $8 \mathrm{~km}$ from the airports for all periods of day, with differences between calculated sound levels being mostly small $(<1 \mathrm{~dB})$, and also for legal requirements, already the simplest approach (CAS) describes time-of-day-specific changes in air traffic with sufficient accuracy. Also, the comparison with monitoring measurements in the vicinity of the airports does not allow preferring one or the other method (Fig. 6). Larger differences in sound levels mostly occur in regions further away from the airports (within a perimeter of $16-17 \mathrm{~km}$ around the airports, $10 \%$ of the total area showed differences $\geq 1 \mathrm{~dB}$ ). Thus, CAS will usually yield sufficiently accurate results, at least for surveys. Nevertheless, CPC with its great level of detail has important advantages over CPS and particularly also over CAS: CPC completely accounts for any variation in flight paths and their dispersion over the $24 \mathrm{~h}$ of a day, yielding more accurate results than CPS and CAS, particularly for short time periods and remote areas. Also, CPC considers every single flight over 1 year's flight operation. This avoids any discussion of not having taken into consideration exceptional flight events, which will in turn increase the acceptance in the population and will thus be politically important.

As the simulation program FLULA2 already used radar data in calculations prior to this study whenever available (Bütikofer et al., 1999), the step from a random selection of a subset of flight paths (CAS) to specific footprint-calculations per time period based on a complete radar dataset (CPC) was relatively small, and the required extra effort (mostly computational time and data handling) is manageable, though not negligible. The main disadvantage is that one needs to perform separate footprint-calculations for every required period of day, in comparison to one single footprint-calculation of CAS (Table II). Nevertheless, as CPC enhances the accuracy of the noise contours, and as these entail important legal consequences, the authors think that CPC is well worth the extra effort and recommend applying this approach wherever radar data are available. The CPC approach represents the state of the art of aircraft noise calculation in Switzerland. It has been used to determine the noise contours around Zurich airport since 2006, and was also successfully applied to Geneva airport for 2008. Thus CPC is not just an "academic solution" but also an engineering model applicable in practice. Future research to improve results should focus on the implementation of meteorological and ground effects, refined sound source data, and in particular on more detailed power settings to consider variations in aircraft performance during departure or approach.

\section{ACKNOWLEDGMENTS}

The authors would like to thank Martin Bissegger, Daniel Dumas, Pascal Helfer, and Edith Hug (in alphabetic order) for the monitoring and radar data and general information on Zurich and Geneva airports, and Walter Krebs for the stimulating discussions regarding this study. The work was funded in part by Flughafen Zürich AG (assignment No. 445518), by Geneva International Airport (assignment No. 452621), 
and by the Federal Office of Civil Aviation (FOCA) (assignment No. 452623), which is gratefully acknowledged. The Swiss National Science Foundation is acknowledged for partly financing the IPAZIA computational cluster (project 206021_128754) used for the calculations.

\section{NOMENCLATURE}

CAS Modeling approach: Calculation of averaged footprints based on a subset of flight geometries (one footprint per aircraft type and air route as an average over the $24 \mathrm{~h}$ of a day)

CPC Modeling approach: Calculation of period-of-dayspecific footprints based on a complete set of flight geometries (one footprint per aircraft type, air route, and period of day)

CPS Modeling approach: Calculation of period-of-dayspecific footprints based on a subset of flight geometries (one footprint per aircraft type, air route, and period of day)

$L$ Sound level (e.g., $L_{\text {Aeq,d }}, L_{\text {Aeq,n1 }}$, and $L_{\text {Aeq,n2 }} ; L_{d}$, $L_{e}, L_{n}$, and $\left.L_{\mathrm{den}}\right)$

$L_{\mathrm{AE}} \quad$ Single event level

$L_{\text {Aeq }} \quad$ Equivalent continuous sound level

$L_{\text {Aeq,d }} \quad$ Noise of the traffic of large aircraft during the day from 06 to $22 \mathrm{~h}$ on a yearly average

$L_{\text {Aeq,n1 }} \quad$ Noise of the traffic of large aircraft during the first hour of the night from 22 to $23 \mathrm{~h}$ on a yearly average

$L_{\text {Aeq,n2 }} \quad$ Noise of the traffic of large aircraft during the second hour of the night from 23 to $24 \mathrm{~h}$ on a yearly average

$L_{\text {Aeq,n3 }}$ Noise of the traffic of large aircraft during the last hour of the night from 05 to $06 \mathrm{~h}$ on a yearly average

$L_{d} \quad$ Noise of the traffic of large aircraft during the day from 06 to $18 \mathrm{~h}$ on a yearly average used to determine the $L_{\text {den }}$

$L_{\text {den }} \quad$ Day-evening-night level

$L_{e} \quad$ Noise of the traffic of large aircraft during the evening from 18 to $22 \mathrm{~h}$ on a yearly average used to determine the $L_{\mathrm{den}}$

$L_{n} \quad$ Noise of the traffic of large aircraft during the night from 22 to $06 \mathrm{~h}$ on a yearly average used to determine the $L_{\text {den }}$

NAO Noise abatement ordinance (Swiss legislation)

$\Delta L$ Absolute difference in the sound immission levels as determined by $\mathrm{CPC}$ and $\mathrm{CAS}$

1. FlugLSV (2008). Erste Verordnung zur Durchführung des Gesetzes zum Schutz gegen Fluglärm (Verordnung über die Datenerfassung und das Berechnungsverfahren für die Festsetzung von Lärmschutzbereichen-1. FlugLSV) vom 27. Dezember 2008 (BGBl. I S. 2980) (First Ordinance for the Implementation of the Law for the Protection against Aircraft Noise (Ordinance on the Data Acquisition and the Calculation Method for the Designation of Noise Protection Areas-1. FlugLSV) of 27 December 2008 (BGBl. I p. 2980)) (Berlin, Germany).

BAFU (2002). Noise Abatement in Switzerland. Status and Perspectives. Environmental Series No. 329, Noise. (Federal Office for the Environment (BAFU/FOEN), Berne), available online at http://www.bafu.admin.ch/ publikationen/publikation/00479/index.html?lang=en (Last viewed September 28, 2010).

Basner, M., Samel, A., and Isermann, U. (2006). "Aircraft noise effects on sleep: Application of the results of a large polysomnographic field study," J. Acoust. Soc. Am. 119, 2772-2784.

Bolt, R. H. (1953). "The aircraft noise problem," J. Acoust. Soc. Am. 25, 363-366.

Boulanger, P., Waters-Fuller, T., Attenborough, K., and Li, K. M. (1997). "Models and measurements of sound propagation from a point source over mixed impedance ground," J. Acoust. Soc. Am. 102, 1432-1442.

Brink, M., Wirth, K. E., Schierz, C., Thomann, G., and Bauer, G. (2008). "Annoyance responses to stable and changing aircraft noise exposure," J. Acoust. Soc. Am. 124, 2930-2941.

Buret, M., Li, K. M., and Attenborough, K. (2006). "Optimisation of ground attenuation for moving sound sources," Appl. Acoust. 67, 135-156.

Bütikofer, R. (2007). "Concepts of aircraft noise calculations," Acta. Acust. Acust. 93, 253-262.

Bütikofer, R., and Thomann, G. (2001). "Validation of FLULA, a time-step model for aircraft noise calculations," in Proceedings of the 2001 International Congress and Exhibition on Noise Control Engineering (Inter-Noise 2001), August 27-30, 2001, The Hague, The Netherlands, edited by R. Boone (on the CD-ROM: ISBN 90-806554-2-2, available from Nederlands Akoestisch Genootschap (NAG), 6200 AL Maastricht, The Netherlands), pp. 2359-2364.

Bütikofer, R., and Thomann, G. (2009). "Uncertainty and level adjustments of aircraft noise measurements," in Proceedings of the 2009 International Congress and Exposition on Noise Control Engineering (Inter-Noise 2009), August 23-26, 2009, Ottawa, Canada, edited by J. S. Bolton, B. Gover, and C. Burroughs (on the CD-ROM, available from Institute of Noise Control Engineering, Indianapolis, IN, 46268), paper in09_143.

Bütikofer, R., Thomann, G., and Plüss, S. (1999). "Track dispersion in aircraft noise modeling," in Proceedings of the 1999 Forum Acusticum, 137th meeting of the Acoustical Society of America and the 2nd convention of the European Acoustics Association, integrating the 25th German Acoustics DAGA Conference, March 14-19, 1999, Berlin, Germany, edited by Deutsche Gesellschaft für Akustik (on the CD-ROM: Collected Papers from the Joint Meeting "Berlin 99," ISBN 3-9804568-5-4, available from Deutsche Gesellschaft für Akustik e.V. (DEGA), Universität Oldenburg, Physik/Akustik, 26111 Oldenburg, Germany), paper 3ANSC_10.

CFR (1984). Title 14: Aeronautics and Space, Subchapter I-Airports, Part 150-Airport Noise Compatibility Planning. Doc. No. 18691, 49 FR 49269, with amendments; e-CFR data is current as of September 24, 2010 (Code of Federal Regulations (CFR), United States Government Printing Office, Washington, DC), available online at http://ecfr.gpoaccess.gov/ cgi/t/text/text-idx?c=ecfr\&sid=a5158aa639032dbf09d149fc955658f2\&rgn $=$ div $5 \&$ view $=$ text $\&$ node $=14: 3 \cdot 0 \cdot 1 \cdot 3.18 \& i d n o=14$ (Last viewed September 28, 2010).

Clemente, J., Gaja, E., Clemente, G., and Reig, A. (2005). "Sensitivity of the FAA Integrated Noise Model to input parameters," Appl. Acoust. 66, 263-276.

Der Bundesminister des Inneren (1975). Anleitung zur Berechnung von Lärmschutzbereichen an zivilen und militärischen Flugplätzen nach dem Gesetz zum Schutz gegen Fluglärm vom 30. März 1971 (BGBl I S. 282) (Directive for the Calculation of Noise Protection Areas around Civil and Military Airports according to the Law for the Protection against Aircraft Noise of 30 March 1971 (BGBl I p. 282)). GMBl 26, Ausg. A, Nr. 8 (Bonn, Germany), pp. 162-227.

ECAC (2005a). Doc.29: Report on Standard Method of Computing Noise Contours Around Civil Airports, Volume 1: Applications Guide, 3rd ed. (European Civil Aviation Conference (ECAC)), available online at http:// www.ecac-ceac.org/index.php?content=docstype \&idtype $=38$ (Last viewed September 28, 2010).

ECAC (2005b). Doc.29: Report on Standard Method of Computing Noise Contours Around Civil Airports, Volume 2: Technical Guide, 3rd ed. (European Civil Aviation Conference (ECAC)), available online at http:// www.ecac-ceac.org/index.php?content=docstype\&idtype $=38$ (Last viewed on September 28, 2010).

Embleton, T. F. W. (1996). "Tutorial on sound propagation outdoors," J. Acoust. Soc. Am. 100, 31-48.

Empa (2010). FLULA2, Ein Verfahren zur Berechnung und Darstellung der Fluglärmbelastung. Technische Programm-Dokumentation (FLULA2, a Method for the Calculation and Illustration of Aircraft Noise Exposure. Technical Program Documentation), Version 4 (Empa, Swiss Federal 
Laboratories for Materials Science and Technology, Laboratory of Acoustics/Noise Control, Dübendorf), available online at http://wwws.empa.ch/ plugin/template/empa/*/99854 (Last viewed September 28, 2010).

European Union (2002). Directive 2002/49/EC of the European Parliament and of the Council of 25 June 2002 Relating to the Assessment and Management of Environmental Noise (European Union, Bruxelles), available online at http://eur-lex.europa.eu/LexUriServ/LexUriServ.do?uri=OJ:L: 2002:189:0012:0025:EN:PDF (Last viewed September 28, 2010).

Fleming, G. G., Senzig, D. A., and Clarke, J.-P. B. (2002). "Lateral attenuation of aircraft sound levels over an acoustically hard water surface: Logan airport study," Noise Control Eng. J. 50, 19-29.

Gilbert, K. E., Raspet, R., and Di, X. (1990). "Calculation of turbulence effects in an upward-refracting atmosphere," J. Acoust. Soc. Am. 87, 2428-2437.

Gulding, J. M., Olmstead, J. R., Fleming, G. G., Bryan, R., Mirsky, L., D'Aprile, J., and Gerbi, P. J. (1999). Integrated Noise Model (INM), Version 6.0, User's Guide. Report No. FAA-AEE-99-03 (Federal Aviation Administration (FAA), U.S. Department of Transportation, Washington, DC).

Isermann, U., Matschat, K., Müller, E.-A., and Nitsche, V. (1989). "The effect of air traffic increase and phasing-out of stage 2 aircraft on the noise exposure around airports," in Proceedings of the 1989 International Conference on Noise Control Engineering (Inter-Noise 1989), December 4-6, 1989, Newport Beach, California, edited by G. C. Mailing, Jr. (ISBN 0931784-20-4, available from Noise Control Foundation, Arlington Branch Poughkeepsie, NY 12603), pp. 681-684.

Ismail, M. R., and Oldham, D. J. (2002). "The effect of the urban street canyon on the noise from low flying aircraft," Build. Acoust. 9, 233-251.

Jarup, L., Babisch, W., Houthuijs, D., Pershagen, G., Katsouyanni, K., Cadum, E., Dudley, M.-L., Savigny, P., Seiffert, I., Swart, W., Breugelmans, O., Bluhm, G., Selander, J., Haralabidis, A., Dimakopoulou, K., Sourtzi, P., Velonakis, M., and Vigna-Taglianti, F. (2008). "Hypertension and exposure to noise near airports: The HYENA study," Environ. Health Perspect. 116, 329-333.

Krebs, W., Bütikofer, R., Plüss, S., and Thomann, G. (2003). "Modeling of three-dimensional sound directivity patterns of helicopters," Acta. Acust. Acust. 89, 273-279.

Krebs, W., Bütikofer, R., Plüss, S., and Thomann, G. (2004). "Sound source data for aircraft noise simulation," Acta. Acust. Acust. 90, 91-100.

Krebs, W., Bütikofer, R., Plüss, S., and Thomann, G. (2006). "Spectral three-dimensional sound directivity models for fixed wing aircraft," Acta. Acust. Acust. 92, 269-277.

Krebs, W., and Thomann, G. (2009). "Aircraft noise: New aspects on lateral sound attenuation," Acta. Acust. Acust. 95, 1013-1023.

Kroesen, M., and Bröer, C. (2009). "Policy discourse, people's internal frames, and declared aircraft noise annoyance: An application of Q-methodology," J. Acoust. Soc. Am. 126, 195-207.

Makarewicz, R. (2004). "Noise reduction through source rerouting (L)," J. Acoust. Soc. Am. 116, 2735-2737.

Makarewicz, R. (2010). "Prediction of noise reduction through vehicle path rerouting,” J. Acoust. Soc. Am. 127, 216-222.
Michaud, D. S., Fidell, S., Pearsons, K., Campbell, K. C., and Keith, S. E. (2007). "Review of field studies of aircraft noise-induced sleep disturbance," J. Acoust. Soc. Am. 121, 32-41.

Miedema, H. M. E., and Oudshoorn, C. G. M. (2001). "Annoyance from transportation noise: Relationships with exposure metrics DNL and DENL and their confidence intervals," Environ. Health Perspect. 109, 409-416.

Miedema, H. M. E., and Vos, H. (1998). "Exposure-response relationships for transportation noise," J. Acoust. Soc. Am. 104, 3432-3445.

MPD (2007). European Commission, Directorate-General for Energy and Transport, Directorate F-Air Transport. Study of Aircraft Noise Exposure at and around Community Airports: Evaluation of the Effect of Measures to Reduce Noise. Final report, Tender No. TREN/F3/15-2006 (MPD Group Limited, London, UK), available online at http://ec.europa.eu/transport/air_portal/environment/studies/doc/aircraft_noise_exposure_en.pdf (Last viewed September 28, 2010).

NAO (1986). Lärmschutz-Verordnung (LSV) vom 15. Dezember 1986 (Stand am 1. August 2010) (Noise Abatement Ordinance (NAO) from 15 December 1986 (Effective 1 August 2010)). SR 814.41, available online at http:// www.admin.ch/ch/d/sr/8/814.41.de.pdf (Last viewed on September 28, 2010).

Olmstead, J. R., Fleming, G. G., Gulding, J. M., Roof, C. J., Gerbi, P. J., and Rapoza, A. S. (2001). Integrated Noise Model (INM), Version 6.0, Technical Manual. Report No. FAA-AEE-01-04 (Federal Aviation Administration (FAA), U.S. Department of Transportation, Washington, DC).

Page, J. A., Plotkin, K. J., Downing, J. M., and Lucas, M. (2001). Rotorcraft Noise Model. User Guide. Wyle Report WR 01-09 (Wyle, Arlington, VA).

Pearsons, K. S., Barber, D. S., Tabachnick, B. G., and Fidell, S. (1995). "Predicting noise-induced sleep disturbance," J. Acoust. Soc. Am. 97, 331-338.

Pietrzko, S., and Hofmann, R. F. (1988). "Prediction of A-weighted aircraft noise based on measured directivity patterns," Appl. Acoust. 23, 29-44.

Salomons, E. M. (2001). Computational Atmospheric Acoustics (Kluwer Academic Publishers, Dordrecht, The Netherlands), 335 pp.

Schäffer, B., Plüss, S., Thomann, G., and Bütikofer, R. (2009). "Aircraft noise calculations for relevant periods of day using a complete set of radar data," in Proceedings of the NAG/DAGA 2009, International Conference on Acoustics, including the 35th German Annual Conference on Acoustics (DAGA), March 23-26, 2009, Rotterdam, The Netherlands, edited by M. M. Boone (on the CD-ROM: ISBN 978-3-9808659-6-8, available from Deutsche Gesellschaft für Akustik e.V. (DEGA), 13355 Berlin, Germany), pp. 1414-1417.

Scherebnyj, K., and Hodgson, M. (2007). "Prediction of noise levels and annoyance from aircraft run-ups at Vancouver International Airport," J. Acoust. Soc. Am. 122, 1937-1945.

Thomann, G. (2007). Mess- und Berechnungsunsicherheit von Fluglärmbelastungen und ihre Konsequenzen (Uncertainties of Measured and Calculated Aircraft Noise and Consequences in Relation to Noise Limits), Ph.D. dissertation, Diss. ETH Nr. 17433, ETH Zurich, Zurich, Switzerland, available online at http://e-collection.ethbib.ethz.ch/view/eth:29931 (Last viewed on September 28, 2010). 